\title{
Association of High Blood Pressure with Elevated Oxidative Stress, Inflammatory Marker and Albuminuria in Chronic Kidney Disease Patients
}

\author{
Mochammad Thaha, ${ }^{1}$ Ika N Kadariswantiningsih, ${ }^{2}$ Maulana A Empitu ${ }^{3}$
}

\begin{abstract}
Background: Activation of renin-Angiotensin system in hypertension was believed to be major determinant in endothelial dysfunction, micro-inflammation, and reactive oxygen species generation. This study aimed to investigate the interaction of increased blood pressure with cardiovascular risk factors in chronic kidney disease (CKD).

Materials \& methods: The study was an observational study with cross-sectional design that consecutively enrolled CKD patients in Universitas Airlangga Hospital and two other hospitals in Surabaya, Indonesia. The resting blood pressure and kidney functions of the participants were examined. Malondialdehyde (MDA) and total antioxidant capacity (TAC) was measured in serum and used as oxidative stress markers. Serum hs-C-reactive protein (CRP), lymphocyte-to-monocyte ratio and platelet-tolymphocyte ratio were utilized as inflammatory markers, while urine albumin-to-creatinine ratio (ACR) was used as renal disease marker. The participants were grouped based on their systolic and diastolic blood pressure (SBP and DBP). The difference of marker levels between groups was tested using MannWhitney test. The correlation between SBP and DBP with inflammation, oxidative stress, and albuminuria was determined using Spearman's test.

Results: As many as 7 I patients with CKD were enrolled in this study. As much as $37 \%$ of the participants had high SBP and I4\% had high DBP. High SBP positively associated with MDA $(P<0.05)$, hs-CRP $(P<0.05)$, platelet-to-lymphocyte ratio $(P<0.05)$, and $A C R(P<0.000 I)$ and negatively with lymphocyte-to-monocyte ratio $(P<0.05)$ and TAC $(P<0.000 I)$. High DBP associated positively with $A C R(P<0.05)$ and negatively with TAC $(P<0.05)$.

Conclusions: High systolic or diastolic blood pressure was significantly associated with inflammation, oxidative stress and albuminuria. Optimal blood pressure control may be one of strategies to prevent inflammation and oxidative stress among CKD patients.
\end{abstract}

Keywords: Hypertension, inflammation, oxidative stress, albuminuria, chronic kidney disease.

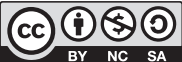

DOI: http://dx.doi.org/l0.3329/jom.v20il.388/5

Copyright: (C) 2019 Thaha $M$ et al. This is an open access article published under the Creative Commons Attribution-NonCommercial-NoDerivatives 4.0 International License, which permits use, distribution and reproduction in any medium, provided the original work is properly cited, is not changed in any way and it is not used for commercial purposes.

Received: 29 November, 2017;

Accepted: 07 March, 2018

1. Department of Internal Medicine, Faculty of Medicine, Universitas Airlangga - Universitas Airlangga Hospital, Indonesia.

2. Department of Medical Microbiology, Faculty of Medicine, Universitas Airlangga, Indonesia.

3. Department of Pharmacology and Therapeutics, Faculty of Medicine, Universitas Airlangga, Indonesia.

Corresponding Author: Maulana A Empitu, Department of Pharmacology and Therapeutics, Faculty of Medicine, Universitas Airlangga, Indonesia. Email: maulana.antiyan@fk.unair.ac.id, Telephone: +628155949095 .
Introduction:

Chronic kidney disease (CKD) and hypertension are both major global health problems. The current prevalence of high blood pressure is estimated around 18-31\% globally, while CKD prevalence was $10 \%$ among South East Asian countries in 2013. ${ }^{1}$ Both of the disorders frequently coincide as blood pressure typically increase with declined kidney function and associated with poor outcomes. ${ }^{2}$ However, adverse cardiovascular events in CKD is the result of interactions between multiple risk factors rather than a contribution of single factor. ${ }^{2}$ 
Inflammation and oxidative stress are two of non-traditional cardiovascular risk factors in CKD. Oxidative stress which is resulted from the imbalance of oxidant and anti-oxidant system. In hypertensive non-CKD population, activation of the renin-angiotensin system has been proposed as a mediator of $\mathrm{NAD}(\mathrm{P}) \mathrm{H}$ oxidase activation and reactive oxygen species (ROS) production. ${ }^{3}$ Multiple studies have shown consistent association between inflammation and adverse cardiovascular event in patients with CKD. ${ }^{4,5}$ Hypertension acts as major determinant of endothelial dysfunction promoting inflammatory response in vascular damage. ${ }^{6}$ It has been shown in experimental model that hypertension promote expression of pro-inflammatory cytokines. ${ }^{6}$

On the other hands, high blood pressure is a mechanical stress to glomerulus which strongly associated with progression of CKD. The mechanical stressed that increases the intra-glomerular pressure initiates the cascade of endothelial damage, podocyte injury, and sclerosis. ${ }^{7}$ In epidemiological study, high Systolic Blood Pressure (SBP) is strong predictor of CKD progression to end-stage renal disease (ESRD) while high Diastolic Blood Pressure (DBP) was consistently associated with higher cardiovascular mortality in CKD. ${ }^{8}$

This study aimed to investigate the association of high SBP and DBP with oxidative stress, inflammation, and CKD progression. The progression of kidney disease can be well monitored using marker of kidney damage such as urinary albumin-to-creatinine ratio (ACR) as demonstrated previously. High-sensitivity $\mathrm{C}$-reactive protein (hs-CRP) is an established inflammatory marker with strong association with cardiovascular mortality in CKD. ${ }^{5}$ In the other hand, higher platelet-to-lymphocyte ratio and lower Lymphocyteto-monocyte ratio were novel predictive marker for higher cardiovascular mortality.9,10 This study compared the oxidative stress, inflammation, and kidney damage markers in CKD patients who had high SBP or DBP.

\section{Materials \& methods: Study design and participants}

This study is an observational clinical study with a crosssectional design. We assumed that the á-value and the expected power for this study were 0.05 and $80 \%$ respectively. With the expected correlation coefficient for blood pressure with inflammation, oxidative stress, and albuminuria was 0.400 , the minimum number of hypertensive patients is 47 based on previously described calculation. ${ }^{11}$

The subjects of this study were patients who visit the internal medicine clinics or hemodialysis units in a government and a private hospital in Surabaya, Indonesia on May to August 2017. All of the subjects were agreed and sign informed consent for this study. The diagnosis of CKD was confirmed by NKF K-DOQI criteria based on CKD-EPI equation (eGFRd" $60 \mathrm{~mL} / \mathrm{min} / 1.73 \mathrm{~m} 2$, urine albumin > $300 \mathrm{mg}$ /day,
Albumin to Creatinine Ratio $>250 \mathrm{mg} / \mathrm{g}$ for men and $>355$ $\mathrm{mg} / \mathrm{g}$ for women). The subjects who had overt infection, malignancy, and fever in the last three days were excluded from this study. The study was approved by Universitas Airlangga Hospital Ethic Committee (Approval number: 093/ IGH/2017) and conducted by research team with Good Clinical Practice certification.

In this study, the study participants were divided based on its systolic blood pressure (SBP) and diastolic blood pressure (DBP) category. High systolic blood pressure (SBP) was defined as SBP greater than $139 \mathrm{mmHg}$, while high DBP was determined if DBP more than $89 \mathrm{mmHg}$. Serum malondialdehyde and total antioxidant capacity were used as oxidative stress marker, while hs-CRP, platelet-tolymphocyte and lymphocyte-to-monocyte ratio as inflammation marker.

\section{Blood pressure measurement}

All BP measurement were performed trained examiner utilizing a standard stethoscope and sphygmomanometer. Resting blood pressure (BP) was measured in a situated position by auscultation utilizing the Riva-Rocci-Korotkoff technique following 5 minutes of rest. Systolic and diastolic BP were controlled by the beginning and vanishing of the Korotkoff sounds (K1 and K5), individually. Proper cuff sizes were chosen by the upper right arm boundary by alluding to procedural guidelines. Three BP readings were taken at 2-minute interims. The least measurement result was utilized in the analysis. The participants of this study were grouped based on their SBP and DBP based on the criteria of hypertension stated in the American College of Cardiology's 2017 Guideline for High Blood Pressure in Adults. High SBP was defined as SBP $>139 \mathrm{mmHg}$ and high DBP means DBP $>89$ mmHg. ${ }^{12}$

\section{Laboratory examination}

The laboratory test measured in this study consisted of leucocyte differential count from peripheral blood cell, serum Malondialdehyde, Total Antioxidant Capacity, and hs-CRP. Serum MDA was measured in blood serum and process by HPLC method using Agilent 1100. The serum TAC measured in blood serum and process by Colorimetry method using Advia 1800. Serum Hs-CRP measured in blood serum and process using particle enhanced turbidimetry (Roche Diagnoostic, CA, USA). The urine level of albumin and creatinine were measured with a Hitachi 7600 using a turbidimetric immunoassay and an enzymatic method, respectively.

\section{Statistical Analysis}

All quantitative data were subject to normality test using Saphiro-Wilk method. Normally distributed values were described as mean and standard deviation (SD) and not normally distributed values were stated as median (interquartile range). Difference of oxidative stress marker level, inflammatory marker, and urine Albumin-to-Creatinine 
ratio between normal and high BP within DBP and SBP groups were calculated using Mann-Whitney test. Difference of marker levels between all groups was tested using Kruskall-Wallis test. Interaction between blood pressure subgroups with oxidative stress marker level, inflammatory marker, and urine Albumin-to-Creatinine ratio were assessed using Spearman test. All comparison test utilized in this study used two-tailed 95\% Confidence Interval. Significant difference was defined if the $\mathrm{p}$-value $<0.05$. Data analysis is supported by XLSTAT version 2016.02.28451.

\section{Results:}

\section{Characteristic of study participants}

Seventy-one patients were evaluated in this study (median age 59 y.o., 41 male). The baseline characteristics of the study participants were described in Table 1. Twenty-six patients (30\%) were on hemodialysis. The median of eGFR was 20 $\mathrm{ml} / \mathrm{minute} / 1.73 \mathrm{~m}^{2}(3-39)$. As much as $73 \%$ of the study participant had type $2 \mathrm{DM}, 87 \%$ had hypertension and $41 \%$ had congestive heart failure.

\section{Comparison of Oxidative Stress Marker Level between SBP and DBP category}

This study divided participants based on its SBP and DBP category, then compared the level of oxidative stress marker. Serum MDA and TAC were used to describe the states of oxidative stress. The MDA level is higher in high SBP $(2.9 \pm$ $0.6 \mathrm{mmol} / \mathrm{L}$ ) compared to normal SBP group (2.4 IQR 2.2-2.9), but there was no different between the high DBP $(3.0 \pm 0.6$ $\mathrm{mmol} / \mathrm{L}$ ) and the normal DBP groups (2.5 IQR 2.2-3.1 mmol/ L) (Fig 1a). Serum TAC were lower in high $\operatorname{SBP}(2.3 \pm 0.7$ $\mathrm{mmol} / \mathrm{L})$ compared to normal SBP $(2.95 \pm 0.7 \mathrm{mmol} / \mathrm{L})$, and

\section{a) hs-CRP}

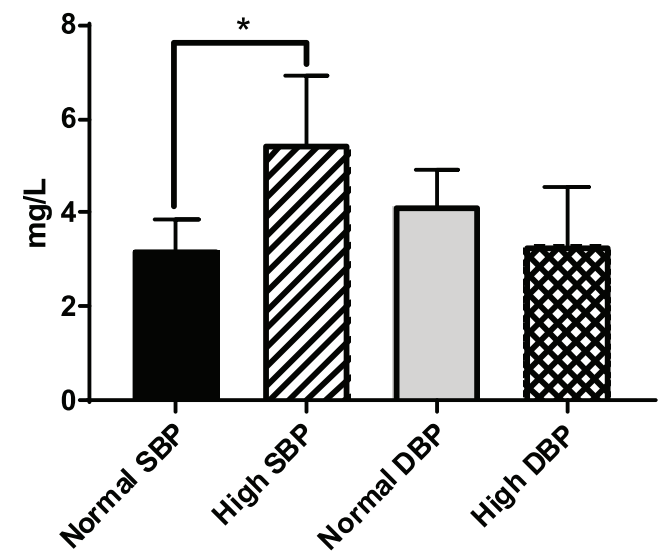

lower in high DBP $(2.3 \pm 0.7 \mathrm{mmol} / \mathrm{L})$ compared to normal $\operatorname{DBP}(2.8 \pm 0.6 \mathrm{mmol} / \mathrm{L})$ groups (Fig $1 \mathrm{~b})$.

Table I: Characteristics of Study Participants

\begin{tabular}{lc}
\hline Characteristic & All participant $(\mathrm{n}=71)$ \\
\hline Age (years) & $59(53-63)$ \\
Sex ratio (M/F) & $41 / 30$ \\
Kidney Function & \\
eGFR (ml/minute/1.73 m2) & $20(3-39)$ \\
Urine ACR & $408(19-2174)$ \\
Serum Creatinine (mg/dL) & $2.9(1.7-12.7)$ \\
Serum Cystatin-C (mg/L) & $2.8(1.7-6.7)$ \\
HD, n $(\%)$ & $26(37)$ \\
Cardiovascular Disease and Risk Factors & \\
Type 2 Diabetes, $\mathrm{n}(\%)$ & $54(76)$ \\
Hypertension, $\mathrm{n}(\%)$ & $62(87)$ \\
High SBP, $\mathrm{n}(\%)$ & $26(37)$ \\
High DBP, $\mathrm{n}(\%)$ & $10(14)$ \\
Chronic heart failure, $\mathrm{n}(\%)$ & $29(41)$ \\
\hline
\end{tabular}

Table II: Spearman's Correlation of Oxidative Stress, Inflammatory Marker, and Urine ACR between groups, we tested their association with high SBP and DBP

\begin{tabular}{lcccc}
\hline & \multicolumn{2}{c}{ High SBP } & \multicolumn{2}{c}{ High DBP } \\
& $\mathrm{r}$ & $\mathrm{P}$ & $\mathrm{r}$ & $\mathrm{P}$ \\
\hline Serum MDA & 0.299 & 0.012 & - & $\mathrm{n} \mathrm{s}$ \\
Serum TAC & 0.504 & $<0,0001$ & 0.277 & 0.020 \\
Hs-CRP & 0.253 & 0.034 & - & $\mathrm{n} \mathrm{s}$ \\
Platelet-to-lymphocyte ratio & 0.272 & 0.022 & - & $\mathrm{n} \mathrm{s}$ \\
Lymphocyte-to-monocyte ratio & -0.235 & 0.048 & - & $\mathrm{ns}$ \\
UrineACR & 0.437 & $<0.0001$ & 0.247 & 0.038 \\
\hline
\end{tabular}

\section{b) Platelet-to-lymphocyte Ratio}

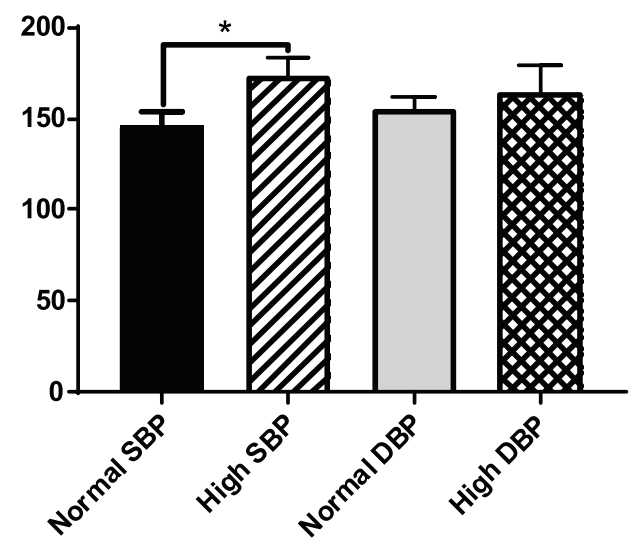

Figure 1: Oxidative stress marker level among study participants. a) Serum MDA level in normal and high SBP as well as $D B P$; b) Serum MDA level in normal and high SBP as well as DBP. * $P<0.05$; ** $P<0.01$; and \#P<0.0001 


\section{Comparison of Inflammatory Markers Level between SBP and DBP category}

This study also compared the level of inflammation among the study participants. Hs-CRP, platelet-to-lymphocyte and lymphocyte-to-monocyte ratio were used to describe the inflammation in CKD patients. Hs-CRP level was higher in high SBP (2.4 IQR 1.5 - $5.9 \mathrm{mg} / \mathrm{L}$ ) compared to normal SBP groups (1.5 IQR 0.9 - $3.5 \mathrm{mg} / \mathrm{L}$ ) (Fig. 2a). Platelet-toLymphocyte ratio was greater in high SBP $(173.5 \pm 52.7)$ compared to normal SBP (144.2 IQR 100.3 - 178) groups (Fig. $2 b)$. Lymphocyte-to-monocyte ratio was lower in high SBP $(3.7 \pm 1.8)$ compared to normal SBP groups $(4.5 \pm 1.5)$ (Fig. 2c).
Comparison of Urine Albumin-to-Creatinine Ratio between SBP and DBP category

To assess the degree of kidney damage, the urine ACR were measured. The Urine ACR were different among the four subgroups $(\mathrm{P}<0.001)$. Urine ACR was higher in high SBP (1789 IQR 587-3646) compared to the normal SBP groups (164 IQR 6 - 990). The urine ACR was also higher in high DBP $(2174 \pm 917-3600)$ compared to normal DBP groups (237 $\pm 10-1789)$ (Fig. 3).

Association between High SBP and DBP with Oxidative Stress, Inflammatory Marker, and Urine Albumin Excretion

After comparing the oxidative stress, inflammatory marker, and urine ACR between groups, this study tested the a) hs-CRP



b) Platelet-to-lymphocyte Ratio

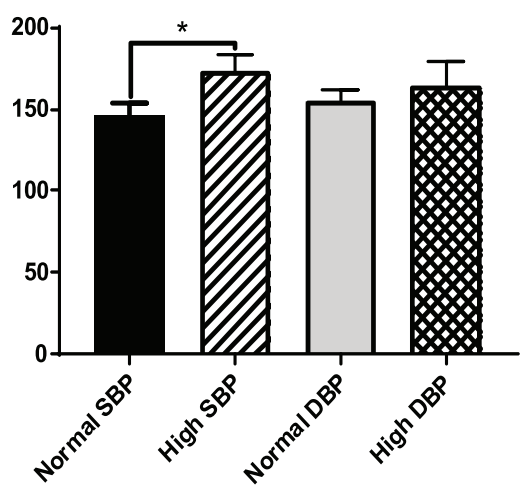

c) Lymphocyte-to-Monocyte Ratio

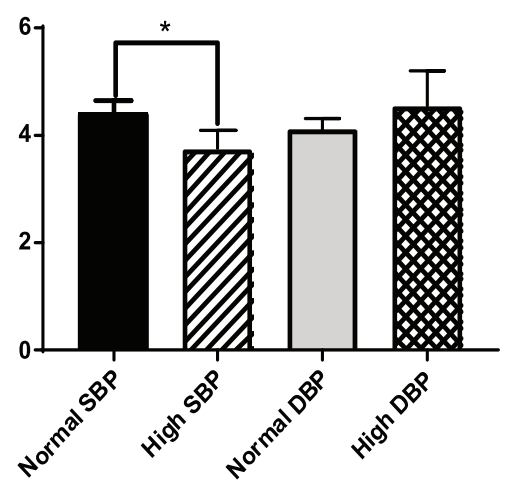

Figure 2: Inflammatory marker level among study participants. a) Serum hs-CRP level; b) Platelet-to-lymphocyte ratio level; and c) Lymphocyte-to-monocyte ratio in normal and high SBP as well as DBP group. * P<0.05

\section{Urin Albumin-to-Creatinine Ratio}

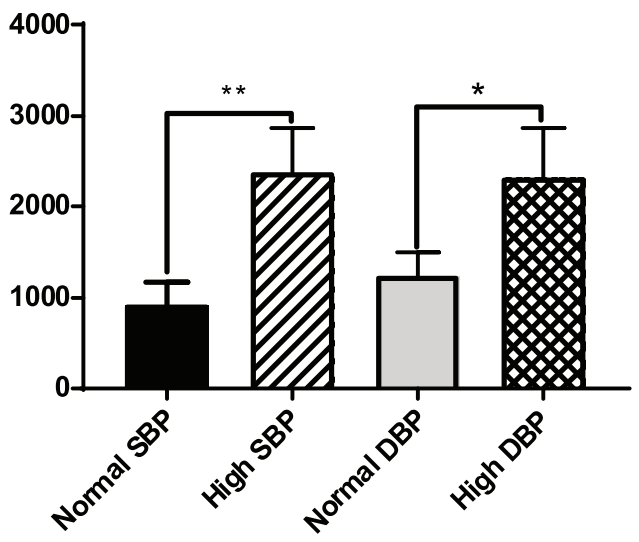

Figure 3. Urine Albumin-to-Creatinine ratio among study participants. $* P<0.05 ; * * P<0.001$ association of those markers with high SBP and DBP. High SBP was associated with serum MDA, TAC, Hs-CRP, Platelet-to-Lymphocyte ratio, Lymphocyte-to-Monocyte ratio and Urine ACR (Table 2). High DBP was only associated serum TAC and Urine ACR.

\section{Discussion:}

Our study showed that both high SBP and DBP associated with some of cardiovascular risk factors in CKD including oxidative stress, inflammation and albuminuria. Participants with high SBP demonstrated increased level of oxidative stress marker and lower level of total antioxidant capacity. Our previous study also found that pro-oxidant state and genetic predisposition factors existed in individual with CKD. ${ }^{13}$ This study result reassured the previous finding which revealed higher MDA level in hypertensive patients. ${ }^{4}$ Malondialdehyde is a marker of lipid peroxidation that increase along with reactive oxygen species (ROS) activity. 
In addition of have higher oxidative stress marker, high SBP group exhibited a lower TAC level. This finding may explain the marked increase in MDA was due to the failure of antioxidant defense, indicated by lower TAC level. Other study by $\mathrm{Xu}$ et al ${ }^{14}$ also revealed that hypertensive CKD patients had increase level of MDA and lower level of antioxidant such as Superoxide dismutase and Glutathione Peroxidase.

Besides having pro-oxidant states, our study showed an association of high SBP with high hs-CRP. Chronic Renal Insufficiency Cohort (CRIC) study demonstrated that increased inflammatory markers were associated with albuminuria and negatively correlated with eGFR. ${ }^{15}$ In a multicenter international kidney disease register, hs-CRP predicted all-cause mortality of hemodialysis patients with precision better than leukocyte counts and ferritin. ${ }^{16}$ Increased plasma hs-CRP was strongly associated with increased body fat, arterial stiffness and cardiovascular mortality both in population with and without CKD. ${ }^{17,18} \mathrm{In}$ experimental model, it has been demonstrated that increased blood pressure promote pro-inflammatory cytokines and endothelial damages. ${ }^{19}$

The rising level of hs-CRP in our study was supported by the finding of increased platelet-to-lymphocyte and lower lymphocyte-to-monocyte ratio in participants with high SBP. Turkmen et al ${ }^{20}$ has previously showed that platelet-tolymphocyte ratio is a reliable marker of inflammation in ESRD with better predictive value compared to neutrophil-tolymphocyte ratio. In non-CKD population, platelet-tolymphocyte ratio demonstrated predictive ability for all-cause mortality after non-ST elevation myocardial infarction. ${ }^{21}$

In the other hand, pro-inflammatory state in CKD is not only a factor that contribute to the progression towards ESRD and mortality, but also occurs as a consequence of decreased renal function and increased cytokines production. Decreased GFR may cause lower clearance of circulating pro-inflammatory cytokines, thus increased the cytokines plasma level. ${ }^{22,23}$

Other factors that increased the pro-inflammatory cytokines production in CKD such as uremia, metabolic acidosis, uncontrolled blood pressure, frequent blood access infection, and thrombosed IV fistula might also contribute to the inflammation. ${ }^{22}$ Uremic state produces oxidative and carbonyl stress which are pro-inflammatory. ${ }^{24}$ The uremic states also contributed to intestinal dysbiosis that was suggested to trigger translocation of gut bacteria into systemic circulation and activate systemic inflammation. ${ }^{25,26}$ As the result, inflammation markers such as IL-6, TNF-alpha, and hs-CRP are increased in CKD patients. ${ }^{15}$
There has been an ample of experimental and clinical evidence that showed hypertension as progression factors of CKD. In this study, the urine ACR was evaluated in patients with increased SBP or DBP. In CKD patients, albuminuria is strongly associated with arterial stiffness and currently used as a progression marker of kidney damage. ${ }^{27}$ Our result showed that both groups of participants with high SBP or DBP had higher urine ACR compared to their normal counterparts respectively. The previous study also revealed similar finding that normotensive individuals are less likely to develop albuminuria. ${ }^{28}$ In the context of outcomes and mortality prediction, albuminuria was comparable to hsCRP. ${ }^{16}$ Considering the study result that showed the interaction of increased blood pressure with oxidative stress and inflammation, implied that a proper blood pressure control in CKD patients may delay CKD progression and reduce cardiovascular risk. Our previous study showed that an intervention to reduce oxidative stress decreased the surrogate marker level of endothelial dysfunction. ${ }^{29}$

\section{Conclusions:}

This study result should be viewed with its limitation. Considering the cross sectional design of this study, the association of increased SBP and DBP with other cardiovascular risk factors did not infer any causality relationship. The weak and moderate association of SBP and DBP with inflammation and stress oxidative also might result from the small size of study participants.

In overall, this study is able some degree of association between high SBP and DBP with several non-traditional cardiovascular risk in CKD. However, further investigation with proper design is highly needed to evaluate the long term outcome and cost effectiveness of managing blood pressure while directly targeting inflammation and stress oxidative in CKD patients.

\section{Conflict of interest: None.}

\section{References:}

1. Jha V, Garcia-Garcia G, Iseki K, Li Z, Naicker S, Plattner B, et al. Chronic kidney disease: global dimension and perspectives. Lancet. 2013;382(9888):260-72. https:// doi.org/10.1016/S0140-6736(13)60687-X

2. Go AS, Chertow GM, Fan D, McCulloch CE, Hsu C. Chronic kidney disease and the risks of death, cardiovascular events, and hospitalization. N Engl J Med. 2004;351(13):1296-305. https://doi.org/10.1056/NEJMoa041031

3. Paravicini TM, Touyz RM. NADPH oxidases, reactive oxygen species, and hypertension: clinical implications and therapeutic possibilities. Diabetes Care. 2008;31(Supplement 2):S170-80. https://doi.org/10.2337/dc08-s247

4. Ahmad A, Singhal U, Hossain MM, Islam N, Rizvi I. The role of the endogenous antioxidant enzymes and 
malondialdehyde in essential hypertension. J Clin diagnostic Res JCDR. 2013;7(6):987. https://doi.org/10.7860/JCDR/ $2013 / 5829.3091$

5. Jalal D, Chonchol M, Etgen T, Sander D. C-reactive protein as a predictor of cardiovascular events in elderly patients with chronic kidney disease. J Nephrol. 2012;25(5):719. https://doi.org/10.5301/jn.5000047

6. Grundy SM. Inflammation, hypertension, and the metabolic syndrome. Jama. 2003;290(22):3000-2. https://doi.org/ 10.1001/jama.290.22.3000

7. Empitu MA, Kadariswantiningsih IN, Aizawa M, Asanuma K. MAGI-2 and scaffold proteins in glomerulopathy. Am J Physiol Physiol. 2018;

8. Weiner DE, Tighiouart H, Amin MG, Stark PC, MacLeod B, Griffith JL, et al. Chronic kidney disease as a risk factor for cardiovascular disease and all-cause mortality: a pooled analysis of community-based studies. J Am Soc Nephrol. 2004;15(5):1307-15. https://doi.org/10.1097/ 01.ASN.0000123691.46138.E2

9. Silva N, Bettencourt P, Guimarães JT. The lymphocyte-tomonocyte ratio: An added value for death prediction in heart failure. Nutr Metab Cardiovasc Dis. 2015;25(11):1033-40. https://doi.org/10.1016/j.numecd.2015.07.004

10. Durmus E, Kivrak T, Gerin F, Sunbul M, Sari I, Erdogan O. Neutrophil-to-lymphocyte ratio and platelet-to-lymphocyte ratio are predictors of heart failure. Arq Bras Cardiol. 2015;105(6):606-13. https://doi.org/10.5935/abc.20150126

11. Hulley SB, Cummings SR, Browner WS, Grady DG, Newman TB. Designing clinical research. Lippincott Williams \& Wilkins; 2011.

12. Whelton PK, Carey RM, Aronow WS, Casey DE, Collins KJ, Dennison Himmelfarb C, et al. 2017 ACC/AHA/AAPA/ $\mathrm{ABC} / \mathrm{ACPM} / \mathrm{AGS} / \mathrm{APhA} / \mathrm{ASH} / \mathrm{ASPC} / \mathrm{NMA} / \mathrm{PCNA}$ Guideline for the Prevention, Detection, Evaluation, and Management of High Blood Pressure in Adults. J Am Coll Cardiol [Internet]. 2018 May 15;71(19):e127 LP-e248. Available from: http:/www.onlinejacc.org/content/71/19/ e127.abstract

13. Thaha M, Yusuf M, Empitu MA, Bakarman A, Tomino Y. Distribution of dimethylarginine-dimethylaminohydrolaseII (DDAH2) gene polymorphism in hemodialysis patients. Acta Med Indones. 2013;45(2):83-8.

14. Xu G, Luo K, Liu H, Huang T, Fang X, Tu W. The progress of inflammation and oxidative stress in patients with chronic kidney disease. Ren Fail. 2015;37(1):45-9. https://doi.org/ 10.3109/0886022X.2014.964141

15. Goldstein SL, Leung JC, Silverstein DM. Pro-and antiinflammatory cytokines in chronic pediatric dialysis patients: effect of aspirin. Clin J Am Soc Nephrol. 2006;1(5):979-86. https://doi.org/10.2215/CJN.02291205
16. Bazeley J, Bieber B, Li Y, Morgenstern H, de Sequera P, Combe $\mathrm{C}$, et al. C-reactive protein and prediction of 1-year mortality in prevalent hemodialysis patients. Clin J Am Soc Nephrol. 2011;CJN-00710111. https://doi.org/10.2215/ CJN.00710111

17. Thaha M, Empitu MA, Kadariswantiningsih IN, Nugroho CW, Hasanatuludhhiyah N, Rasyid H, et al. Anthropometrybased Body Fat Percentage Predicts High hs-CRP in Chronic Kidney Disease Patients. Indones Biomed J. 2018;10(2):184 91. https://doi.org/10.18585/inabj.v10i2.397

18. Tsai S-S, Lin Y-S, Lin C-P, Hwang J-S, Wu L-S, Chu P-H. Metabolic syndrome-associated risk factors and highsensitivity C-reactive protein independently predict arterial stiffness in 9903 subjects with and without chronic kidney disease. Medicine (Baltimore). 2015;94(36). https://doi.org/ 10.1097/MD.0000000000001419

19. Grundy SM. Metabolic syndrome update. Trends Cardiovasc Med. 2016;26(4):364-73. https://doi.org/10.1016/ j.tcm.2015.10.004

20. Turkmen K, Erdur FM, Ozcicek F, Ozcicek A, Akbas EM, Ozbicer A, et al. Platelet to lymphocyte ratio better predicts inflammation than neutrophil to lymphocyte ratio in end stage renal disease patients. Hemodial Int. 2013;17(3):3916. https://doi.org/10.1111/hdi.12040

21. Azab B, Shah N, Akerman M, McGinn JT. Value of platelet/ lymphocyte ratio as a predictor of all-cause mortality after non-ST-elevation myocardial infarction. J Thromb Thrombolysis. 2012;34(3):326-34. https://doi.org/10.1007/ s11239-012-0718-6

22. Akchurin M, Kaskel F. Update on inflammation in chronic kidney disease. Blood Purif. 2015;39(1-3):84-92. https:// doi.org/10.1159/000368940

23. Andres-Hernando A, Dursun B, Altmann C, Ahuja N, He Z, Bhargava $\mathrm{R}$, et al. Cytokine production increases and cytokine clearance decreases in mice with bilateral nephrectomy. Nephrol Dial Transplant. 2012;27(12):4339-47. https:// doi.org/10.1093/ndt/gfs256

24. Aveles PR, Criminácio CR, Gonçalves S, Bignelli AT, Claro LM, Siqueira SS, et al. Association between biomarkers of carbonyl stress with increased systemic inflammatory response in different stages of chronic kidney disease and after renal transplantation. Nephron Clin Pract. 2010;116(4):c294-9. https://doi.org/10.1159/000318792

25. Anders H-J, Andersen K, Stecher B. The intestinal microbiota, a leaky gut, and abnormal immunity in kidney disease. Kidney Int. 2013;83(6):1010-6. https://doi.org/ 10.1038/ki.2012.440

26. Ramezani A, Raj DS. The gut microbiome, kidney disease, and targeted interventions. J Am Soc Nephrol. 2014; 25(4):657-70. https://doi.org/10.1681/ASN. 2013080905 
27. Kalaitzidis RG, Karasavvidou DP, Tatsioni A, Pappas K, Katatsis G, Liontos A, et al. Albuminuria as a marker of arterial stiffness in chronic kidney disease patients. World J Nephrol. 2015;4(3):406. https://doi.org/10.5527/ wjn.v4.i3.406

28. Cotter J, Oliveira P, Cunha P, Polónia J. Risk Factors for Development of Microalbuminuria in Diabetic and Nondiabetic Normoalbuminuric Hypertensives with High or Very High Cardiovascular Risk-A Twelve-Month FollowUp Study. Nephron Clin Pract. 2009;113(1):c8-15. https:// doi.org/10.1159/000228070

29. Thaha M, Pranawa W, Yogiantoro M, Tomino Y. Intravenous $\mathrm{N}$-acetylcysteine during hemodialysis reduces asymmetric dimethylarginine level in end-stage renal disease patients. Clin Nephrol. 2008;69(1):24-32. https://doi.org/10.5414/ CNP69024 